\section{Prevalence of osteoporosis- osteopenia at lumbar spine and femur in an urban female population. An epidemiological study in the Athens Metropolitan area, Greece}

loannis Legakis, ${ }^{1}$ Vasilis Papadopoulos², Vasilis Tataridas, 2 and Kyriakos Strigaris 2

1 Department of Endocrinology and 2Department of Radiology, Henry Dunant Hospital, Athens, Greece

\begin{abstract}
The aim of this study is to determine the prevalence of osteoporosis and osteopenia in a female urban population. Dual energy X-ray absorptiometry measurements were done at the lumbar spine (6920 females) and at the femur (3222 females) Bone mineral density (BMD) and corresponding T-scores were analysed using multivariate regression models. In females, the prevalence rate of osteoporosis was $15.3 \%$ at the lumbar spine and of osteopenia $36.5 \%$. In females osteoporosis rate at the femur was $17.7 \%$ for the neck, $30.65 \%$ for the ward's triangle and $1.86 \%$ for the tronchater, whereas the osteopenic rates were $53.3 \%, 44.7 \%$ and $32.09 \%$ respectively. A polynominal cubic model performed for age showed the steepest decline at the age of 55 years for the spine BMD (-0.973\% change, $95 \%$ CI -1.031/-0.915) and at the age of 64 years for the femur BMD (-0.726\% change, 95\% CI $0.793 /-0.658$ ). Actually sensitive interventions for prevention of osteoporosis in urban population need serious concern.
\end{abstract}

\section{Introduction}

Osteoporosis, a major health problem worldwide, $, 1,2$ is characterized by low bone mass and microarchitectural deterioration of bone structure. ${ }^{3,4}$ Bone mass is determined by peak bone mass and the rate of bone loss. Dual-energy Xray absorptiometry (DXA) is a widely used technique to assess bone mineral density (BMD) at different skeletal sites and therefore suitable to stratify individuals with low bone mass who are at risk of osteoporosis and fractures. BMD is influenced by genetic, environmental, and hormonal factors. ${ }^{5}$ Ethnic and racial variations of bone density are therefore expected. ${ }^{6}, 7$ Moreover, age and sex have such a strong impact that reference values for BMD should be age-and sex-specific, and, accord- ingly, for a reliable interpretation of such values, they need to be expressed in terms of established reference values derived from an appropriate healthy population. ${ }^{8}$

The World Health Organization (WHO) defined diagnostic criteria for osteoporosis in terms of BMD as measured by DXA, ${ }^{9}$ and although such criteria are based on observations in postmenopausal Caucasian females, they are widely used and applied to other at risk populations to confirm a diagnosis of osteoporosis. ${ }^{10,11}$ The aim of the present study was to assess the incidence and the prevalence of osteoporosis in a urban female population in Greece. For that reason, DXA measurements were collected and analysed retrospectively.

\section{Materials and Methods}

Data collection was conducted through a 4 year period (2003-2007) from the Radiology Department of the Henry Dunant Hospital in Athens, Greece. Evaluation of the DXA measurements was performed in individuals aged 29 to 89 years, first at the lumbar spine in 6920 females and second at the femur in 3222 females. Participants in the study had no history of atraumatic fractures, menstrual irregularities, or diseases known to affect bone, and were not on any medication known to affect bone metabolism other than oral contraception.

BMD measurements $\left(\mathrm{g} / \mathrm{cm}^{2}\right)$ was determined for the anteroposterior lumbar spine (L2-L4) and mean of proximal right and left femur (total and subregions) by DXA using a Lunar DPX-IQ (Lunar, Madison, WI, USA), according to standard protocol. BMD of the femur was expressed as the mean of the BMD values for the subregions: trochanter, Ward's triangle, and neck. All scans were performed and analysed by the same investigator. Quality control procedures were carried out in accordance with the manufacturer's recommendations.

Instrument variation was determined regularly by a daily calibration procedure using a phantom supplied by the manufacturer. Precision error of the phantom was $0.3 \%$ and for in vivo measurements was less than $1.2 \%$ for the spine and less than $2 \%$ for femoral regions. Lunar Italian normal database supplied by the manufacturer was used to derive $\mathrm{Z}$ scores (matched for age and weight) and $\mathrm{T}$ scores (reference age 20-90 years). Subjects were weighed on an electric scale wearing minimal clothing. Height was measured to the nearest centimeter using a stadiometer. Body mass index (BMI) was calculated as weight divided by height in meters squared $\left(\mathrm{kg} / \mathrm{m}^{2}\right)$. For data analysis, participants were grouped on the basis of 5 -year age increments. The percentage of individuals with osteopenia or
Correspondence: Ioannis Legakis, Department of Endocrinology, Henry Dunant Hospital, Mesogion Avenue 107, Athens, Greece 11526

Fax: + 210.698.5299. E-mail: ilegak@med.uoa.gr

Key words: osteporosis , osteopenia, bone mineral density, dual energy X-ray absorptiometry, T-score, spine, femur, urban population.

Received for publication: 7 September 2011. Revision received: 15 November 2011.

Accepted for publication: 15 November 2011.

This work is licensed under a Creative Commons Attribution NonCommercial 3.0 License (CC BYNC 3.0)

(C) Copyright I. Legakis et al., 2012

Licensee PAGEPress, Italy

Endocrinology Studies 2012; 2:e1

doi:10.4081/es.2012.e1

osteoporosis were calculated according to WHO) criteria. ${ }^{9}$

BMD measurements and the corresponding T-scores were analysed using multivariate regression models. ${ }^{12}$ More specifically, due to nonlinear patterns observed in our data, all models used here included polynomial terms for age up to the third degree (cubic model). All models' assumptions were checked using appropriate tests and graphs. All regression models were also refitted using non-parametric methods as part of a sensitivity analysis. Separate analyses for the spine and femur (neck, Ward's triangle, trochanter) were performed. The significance of somatometric characteristics such as weight, height, and BMI was also investigated. All statistical procedures were performed using Stata 8.2 (Stata corp., TX, USA). The study was approved by the Ethics Committee of the Henry Dunant Hospital.

\section{Results}

The prevalence rate of osteoporosis, based to the WHO criteria, at the lumbar spine in women was $15.3 \%$ and of osteopenia was $36.5 \%$ (Figure 1). The osteoporosis rate at the femur was $17.7 \%$ for the neck, $30.65 \%$ for the ward's triangle and $1.86 \%$ for the tronchater, whereas osteopenic rates at the femur were $53.3 \%$ for the neck, $44.7 \%$ for the ward's triangle and $32.09 \%$ for the trochanter (Figure 2). Initial exploratory analysis revealed that BMD and Tscore age-related changes were not linear across the chronological range of our sample in the female population (20 to 90 years). For that reason, a polynomial cubic model was performed for age which showed good fit for the 
observed data allowing also the estimation of age related slopes to T-scores values. The steepest decline was observed at the age of 55 years (-0.973\% change, $95 \%$ CI -1.031/-0.915) for the spine BMD (Figure 3 ) and at the age of 64 years for the femur BMD measurements $(-0.726 \%$ change, 95\% CI -0.793/-0.658) (Figure 4).

According to our data, each anatomical region displayed a different rate of bone loss. In the female population, the mean yearly percent loss of BMD in the spine was increased until the age of 65 years and thereafter a progressive decrease was observed. Moreover, the mean yearly percent loss in BMD was much greater at the ward's triangle and the neck as compared to trochanter at the femur site (Table 1). Although, as expected, BMI was significantly correlated with BMD and T-scores, weight and height were directly associated with BMD at all measurements sites. No serious violations of the assumptions, for the regression models used in this analysis, were found. Moreover all models have been refitted, as a sensitivity analysis, using non-parametric techniques and all results remained practically unaffected.

\section{Discussion}

Our results showed that the prevalence rates of osteoporosis and osteopenia, according to WHO criteria, in the entire analysed population were at the higher upper limits as compared to similar studies performed in other countries, ${ }^{13,14}$ confirming the observations that racial differences do exist in BMD reference curves. ${ }^{15,16}$ The prevalence of osteoporosis and osteopenia increased with advancing age. Moreover, in females, the steepest decline for T-score values was observed at the age of 54 years for the spine BMD and at the age of 62 years for the femur BMD measurements. Previous studies in normal Greek population ${ }^{17}$ in 244 women reported that the total bone loss between ages 20 and 70 was $29.5 \%$ for the vertebrae and $32 \%$ for the femoral neck. In our study, the percentage of total bone loss in women between ages 35 to 84 was $14.36 \%$ at the spine (L2-L4), $22.97 \%$ for the femoral neck, $32.7 \%$ for the ward's triangle, and $16.27 \%$ for the tronchanter. Concerning population studies, the influence of the body composition to the observed difference in BMD has long been prognostic. In particular, the NHANES III investigators have reported a marked effect of body weight on BMD values in the hip. ${ }^{18}$ In relevance to the above data, our results showed that weight and height had a better fit to the observed data than BMI. Based on the fact that BMI had a significant correlation with BMD and T-scores, we assume that our correlations were made possible due to the large number of the population tested.
It is well known that BMD relates to the risk of fracture, with decreased BMD resulting in increased fracture risk. ${ }^{4,19}$ In particular, bone density in elderly persons is highly relevant to the risk of osteoporotic fracture with the highest rates of osteoporosis-related fractures occuring in elderly women. ${ }^{20-24}$ Nevertheless, after adjustment for body size, race, and sex differences in regional and whole body, bone mass of adults remain at a low level.25,26
According to the literature, men and women may achieve similar peak bone density at the spine and proximal femur. ${ }^{27}$ Bone loss in women may occur earlier and the rate may be twice that in men, ${ }^{28}$ although this sex difference may be smaller in later life. ${ }^{29}$ Our data suggest that bone loss in females both at the spine and the femur occurs earlier in life, namely from 50 years old. The effect of sex steroids might be taken into account to explain

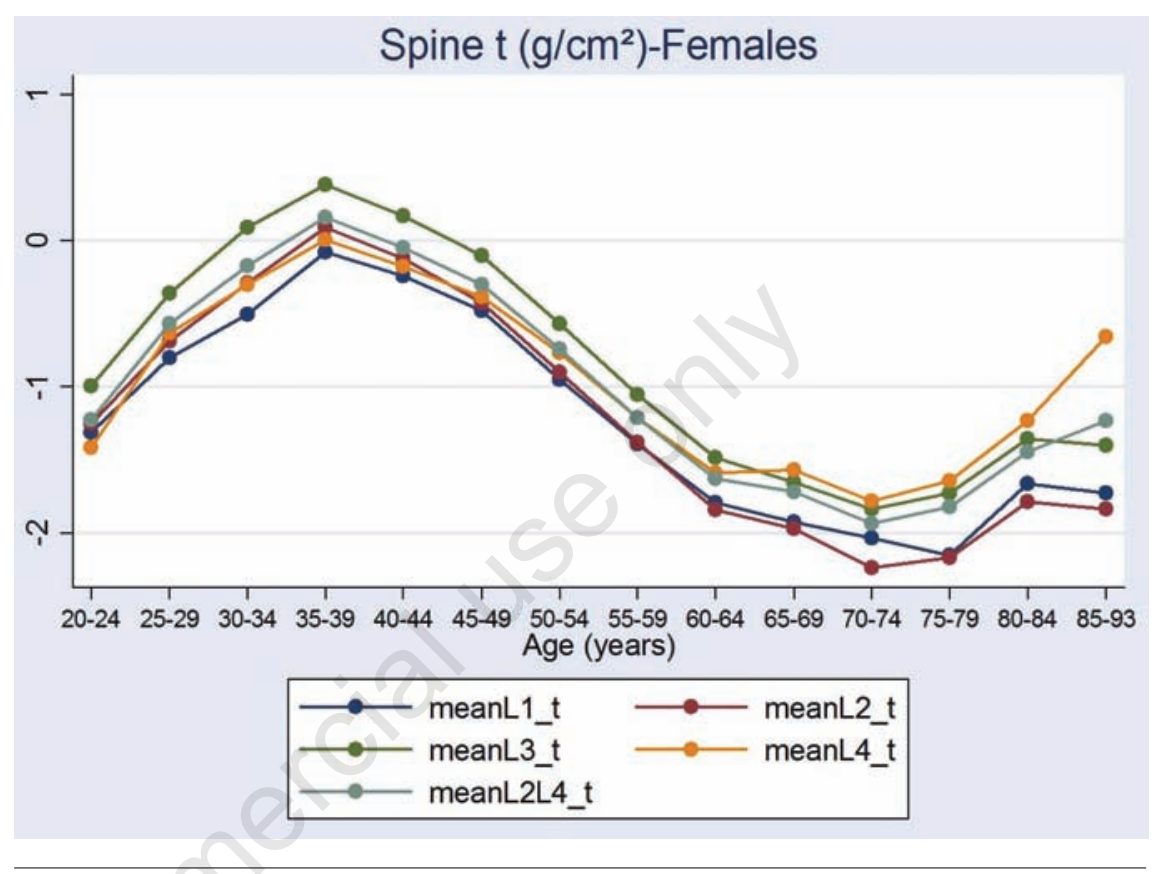

Figure 1. Mean bone mineral density of lumbar spine (L1-L4) in the female population aged $20-93$ years.

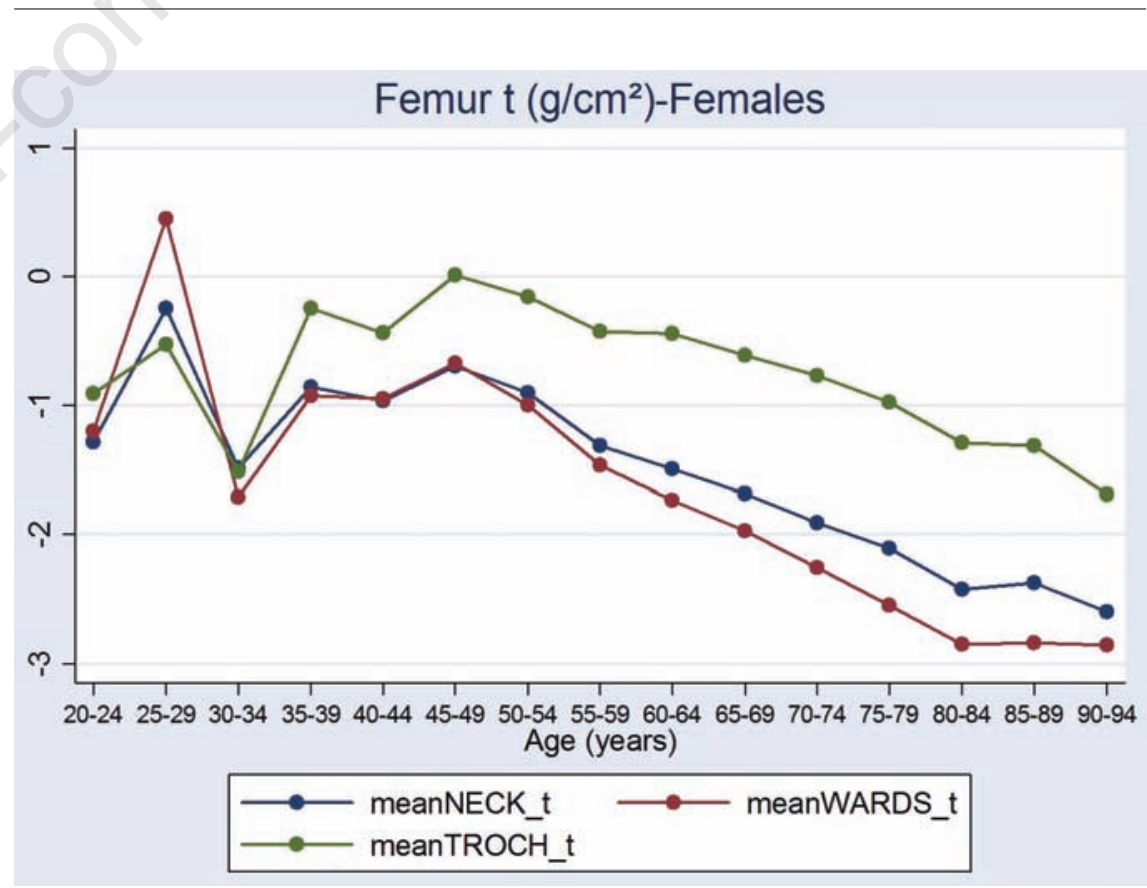

Figure 2. Mean bone mineral density of femoral neck, ward's triangle and tronchanter in the females aged 20-94 years. 
the above data.

Heterogeneity of sites-related BMD was also observed in our female population. Namely, bone loss was first detected at the spine at the age of 50 years. For the same age, osteopenia was detected at the femoral neck and the ward's triangle but not at the throchanter. The steepest and earlier decline of bone loss was observed in the spine reaching $\mathrm{T}$ score $\leq 2.5$ at the age of 70 to 74 years old. The femur, the neck and the ward's triangle were the primary sites of bone loss followed by the trochanter, reaching $\mathrm{T}$ score $\leq 2.5$ at a later age, namely 80 to 90 years.

Conflict results have been reported by several investigators concerning the difference between BMD at various skeletal sites in postmenopausal women when compared with reference means. It has been previously shown ${ }^{30,31}$ that BMD of the spine and femoral neck in postmenopausal women aged 45-60 years tends to be similar when compared with reference means although $26 \%$ of the individuals tested had Z-scores sufficiently different to result in mischaracterization of the fracture risk at the non-measured site. Moreover, Davis et al. ${ }^{32}$ classified women aged 47-82 by tertiles of Zscore for BMD at any one of four skeletal sites and found heterogeneity in BMD at different skeletal sites within an individual. On the other hand, Bonnick et al. ${ }^{33}$ showed that differences in Z-score between the BMD at the lumbar spine and proximal femoral sites are common in healthy premenopausal women and in women aged 30 and more these differences appear to be the result of a decline in BMD at the proximal femur combined with no significant change in BMD at the lumbar spine.

In our study, the yearly mean percent loss in BMD for women was much greater in the ward's triangle and the neck as compared to trochanter at the femur site. Additionally, the yearly mean percent loss in BMD for women in the spine increased from the age of 50 years and, interestingly, a dramatic decrease occurred after the age of 65 years, presumably due to osteophytes and/or therapeutic interventions. Similar results concerning the annual reduction rate in BMD were obtained in the population of a northern part of Greece, ${ }^{34}$ although the absolute values in our study tend to be slightly elevated. It was not possible to deduce similar information regarding the male population in our study due to discrepancy of the results obtained. The use of an Italian reference population could be considered only as a minor limitation of our study since it has been previously found ${ }^{34}$ that this population's normal range is close to the Greek one and can be reliably used at least as T-scores are concerned whereas for Z-scores discrepancies are small.

It is well recognized that BMD and soft tissue mass are mutually dependent from exercise ${ }^{35-39}$ whereas both respond to intrinsic fac- tors such as somatotrophic and sex hormones. ${ }^{40}$ These common hormonal effects are not only important during the rapid growth during adolescence, in which dramatic gains in bone and muscle mass are observed, ${ }^{41}$ but also throughout adult life.

For the people in our study, living in a urban area, physical activity and exercise are not expected to be involved in an every day life accomplishments. Also, in nowadays, elderly in
Athens are exposed less to sunlight and are less active compared with the elderly of previous years. In addition, abuse of sedatives or the interaction between various drugs taken commonly by the elderly are often related to changes in life-style (urbanization of population, institutionalization of elderly) that may have adverse effects on BMD. Osteoarthritis of the spine has been associated with increased BMD at the spine, femoral neck, ${ }^{42}$ and total

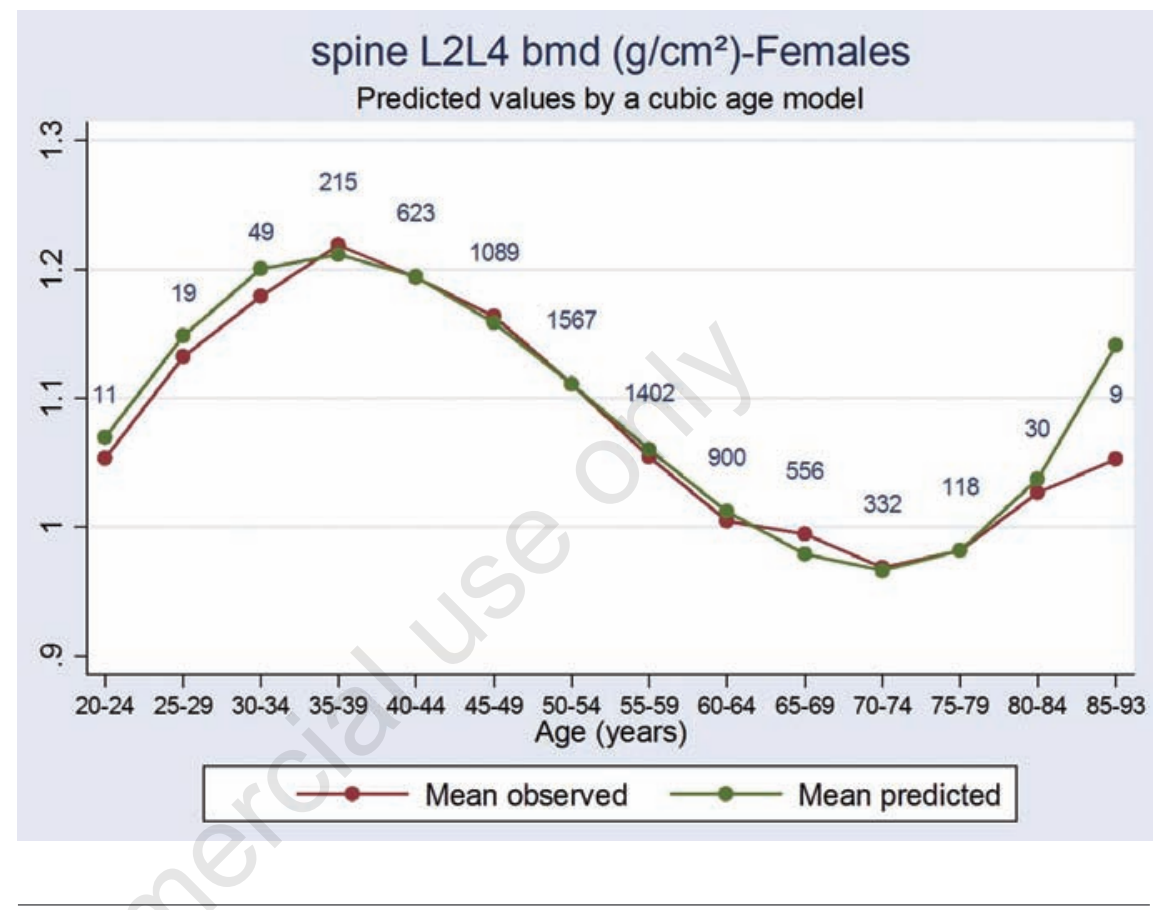

Figure 3. Mean bone mineral density of lumbar spine (L2-L4) observed and predicted by a cubic age model in the female population aged $20-93$ years.

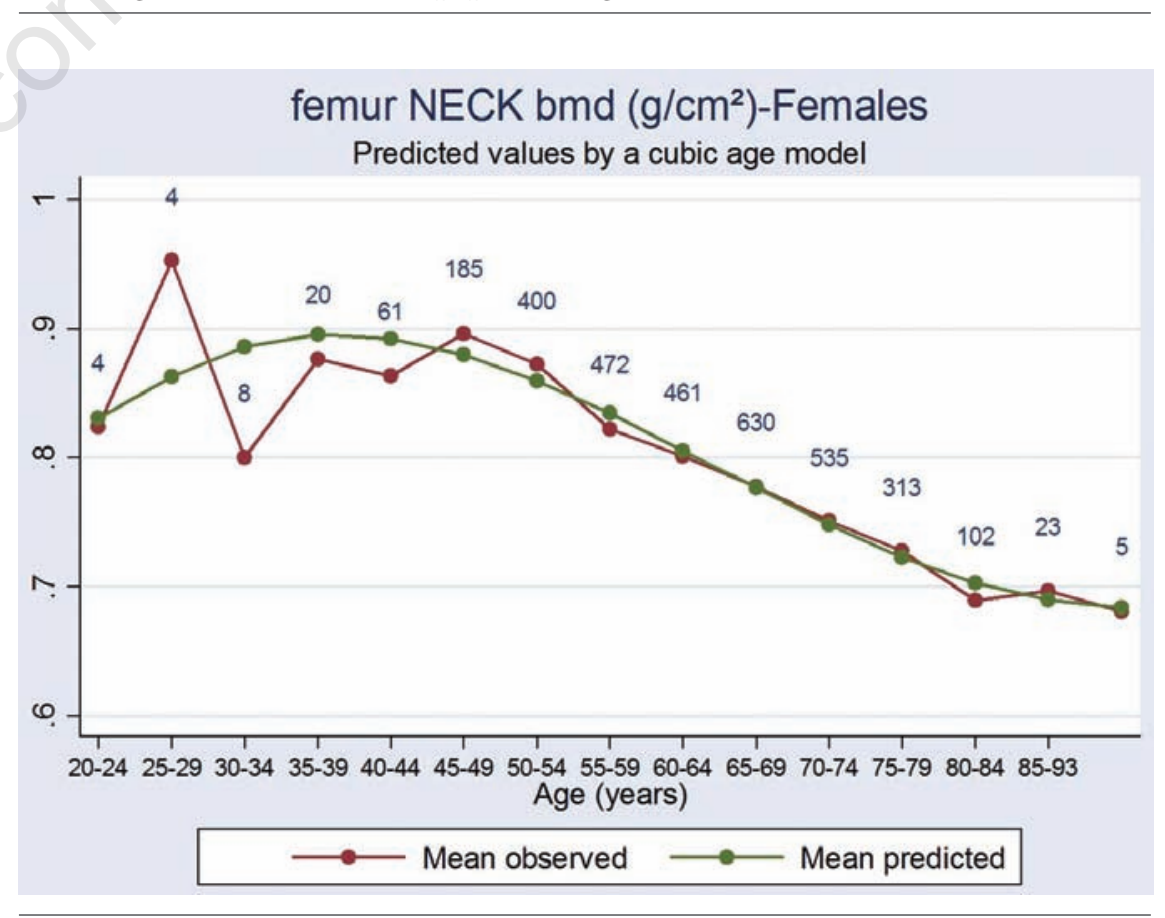

Figure 4. Mean bone mineral density of femoral neck observed and predicted by a cubic age model in the female population aged $20-95$ years. 
body. ${ }^{43}$ However, increased BMD in the region affected by osteoarthritis may be an artifact due to osteophytes, intervertebral joint space narrowing and sclerosis within the region of interest, or may reflect a generalized increase in BMD on the skeleton. ${ }^{43}$ Our results are in agreement with the above data, in that an increase in BMD was observed in the spine after the age of 74 years presumably due to osteoathritic changes.

Low bone density at the femur is a strong predictor of the increased risk for hip fracture. In one of the largest cohort studies of osteoporosis, the Study of Osteoporotic Fractures, women in the lowest quartile of BMD had an 8fold increased risk of hip fracture compared with the women in the highest BMD quartile. ${ }^{44}$ Earlier cross-sectional investigation study of femoral and radius BMD in the Framingham cohort showed that age was inversely related to BMD in both men and women. ${ }^{45}$ Both crosssectional and longitudinal studies have also reported age-related bone loss. ${ }^{46}$

\section{Conclusions}

To our knowledge, this is the first large population based study of osteoporosis and osteopenia in the Greek female population. Provided that early identification of BMD and adequate treatment when indicated are needed to avoid osteoporosis-related fractures and disabilities and in the light of the longer life span, the findings of this study suggest that actually sensitive interventions on osteoporosis risk and prevention have to be seriously concerned. ${ }^{47}$ In addition, work is needed to determine the impact of the lifestyle, the diet ${ }^{48}$ and local environmental conditions on risk factors for health and disease. ${ }^{49}$

\section{References}

1. O'Neill TW, Felsenberg D, Varlow J, et al. The prevalence of vertebral deformity in European men and women: the European vertebral osteoporosis. Study J Bone Miner Res 1996;11:1010-8.

2. Cooper C, Campion G, Melton LJ 3rd.. Hip fractures in the elderly: a worldwide projection. Osteoporosis Int 1992; 2:285-9.

3. Consensus Development Conference. Diagnosis, prophylaxis and treatment of osteoporosis. Am J Med 1993;94:646-50.

4. Kanis JA, Melton LJ 3rd, Christiansen C, et al. The diagnosis of osteoporosis. J Bone Miner Res 1994;9:1137-41.

5. Riggs BL, Melton LJ 3rd. Involutional osteoporosis. N Engl J Med 1986;314:167684.

Table 1. Mean estimated \% yearly rate of bone mineral density change of the spine and femur (neck, ward's triangle, tronchanter) in the female population.

\begin{tabular}{cccc}
\hline Age (years) & \multicolumn{1}{c}{$\begin{array}{c}\text { Region } \\
\text { Estimated \% relative } \\
\text { change per year }\end{array}$} \\
\hline 50 & Spine L2-L4 & -0.903 & $(-0.958,-0.847)$ \\
& Femur neck & -0.536 & $(-0.623,-0.448)$ \\
& Femur wards & -0.793 & $(-0.906,-0.680)$ \\
55 & Femur trochanter & -0.225 & $(-1.031,-0.915)$ \\
& Spine L2-L4 & -0.973 & $(-0.718,-0.565)$ \\
& Femur neck & -0.642 & $(-1,044,-0,845)$ \\
& Femur wards & -0.944 & $(-0.437,-0.275)$ \\
\hline 60 & Femur trochanter & -0.356 & $(-0.942,-0.825)$ \\
& Spine L2-L4 & -0.883 & $(-0.780,-0.633)$ \\
& Femur neck & -0.707 & $(-1.141,-0.948)$ \\
& Femur wards & -1.045 & $(-0.536,-0.384)$ \\
65 & Femur trochanter & -0.460 & $(-0.673,-0.536)$ \\
& Spine L2-L4 & -0.605 & $(-0.793,-0.658)$ \\
& Femur neck & -0.726 & $(-1.175,-0.993)$ \\
& Femur wards & -1.084 & $(-0.608,-0.468)$ \\
\hline 70 & Femur trochanter & -0.538 & $(-0.238,-0.002)$ \\
& Spine L2-L4 & -0.120 & $(-0.769,-0.614)$ \\
& Femur neck & -0.691 & $(-1.154,-0.942)$ \\
& Femur wards & -1.048 & $(-0.666,-0.508)$ \\
75 & Femur trochanter & -0.587 & $(0.351,0.753)$ \\
& Spine L2-L4 & $-0.728,-0.462)$ \\
& Femur neck & 0.552 & $(-1.104,-0.732)$ \\
& Femur wards & -0.595 & $(-0.740,-0.469)$ \\
\hline
\end{tabular}

*Confidence Interval.

6. Lunt M, Felsenberg D, Reeve J, et al. Bone density variation and its effects on risk of vertebral deformity in men and women studied in thirteen European centers: the EVOS study. J Bone Miner Res 1997;12: 1883-94.

7. Alver K, Meyer HE, Falch JA, Søgaard AJ. Bone mineral density in ethnic Norwegians and Pakistiani immigrants living in 0slo -The Oslo Health Study. Osteoporos Int 2005;16:623-30.

8. Lofman 0, Larsson L, Ross I, et al. Bone mineral density in normal Swedish women. Bone 1997;20:167-74.

9. World Health Organization. Assessment of fracture risk and its application to screening for postmenopausal osteoporosis. Technical Support Series. No. 843 Geneva: 1994.

10. Kanis JA. Diagnosis of osteoporosis and assessment of fracture risk. Lancet 2002; 359:1929-36.

11. Cummings SR, Bates D, Black DM. Clinical use of bone densitometry. JAMA 2002;288:1889-97.

12. Kleinbaum GD, Kupper LL, Muller EK. Applied regression analysis and other multivariable methods. Belmont: Thomson Higher Education; 2007.

13. Filip RS, Zagórski J. Bone mineral density and osteoporosis in rural and urban women. Epidemiological study of the Lublin region (Eastern Poland). Ann Agric Environ Med 2001;8:221-6.
14. Holt G, Khaw KT, Reid DM, et al. Prevalence of osteoporotic bone mineral density at the hip in Britain differs substantially from the US over 50 years of age. Implications for clinical densiometry. Br J Radiol 2002;75:736-42.

15. Iki M, Kagamimori S, Kagawa Y, et al. Bone mineral density of the spine, hip and distal forearm in representative samples of the Japanese female population: Japanese Population-Based 0steoporosis (JPOS). Study Osteoporosis Int 2000;12:529-37.

16. Diaz Curiel M, Gracia JJ, Carrasco Jl, et al. Prevalence of osteoporosis assessed by densitometry in the Spanish female population. Med Clin 2001;116:86-88.

17. Hadjidakis D, Kokkinakis E, Giannopoulos G, et al. Bone mineral density of vertebrae, proximal femur and os calcis in normal Greek subjects as assessed by dual-energy X-ray absorptiometry: comparison with other populations. Eur J Clin Invest 1997;27:219-27.

18. Beck TJ, Looker AC, Ruff CB, et al. Structural trends in the ageing femoral neck and proximal shaft: analysis of the third national health and nutrition examination survey dual-energy X-ray absorptiometry data. J Bone Miner Res 2000; 15:2297-308.

19. Cummings SR, Kelsey JL, Nevitt MC, 0'Dowd KJ. Epidemiology of osteoporosis and osteoporotic fractures. Epidemiol Rev 
1985;7:178-208.

20. Ross PD, Davis JW, Vogel JM, Wasnich RD. A critical review of bone mass and the risk of fractures in osteoporosis. Calcif Tissue Int 1990;46:149-161.

21. Melton LJ III, Atkinson EJ, O'Fallon WM, et al. Long-term fracture prediction by bone mineral assessed at different skeletal sites. J Bone Miner Res 1993;8:1227-33.

22. Kellie SE, Brody JA. Sex-specific and racespecific hip fracture rates. Am J Public Health 1990;80:326-8.

23. Barondess DA, Nelson DA, Schlaen SE. Whole body bone, fat, and lean mass in black and white men. J Bone Miner Res 1997;12:967-71.

24. Visser M, Kiel DP, Langlois J, et al. Muscle mass and fat mass in relation to bone mineral density in very old men and women: The Framingham Heart Study. Appl Radiat Isot 1998;49:745-7.

25. Luckey MM, Meier DE, Mandeli JP, et al. Radial and vertebral bone density in white and black women: Evidence for racial differences in premenopausal bone homeostasis. J Clin Endocrinol Metab 1989;69: 762-70.

26. DeSimone DP, Stevens J, Edwards J, et al. Influence of body habitus and race on bone mineral density of the midradius, hip, and spine in aging women. J Bone Miner Res 1998;4:827-30.

27. Slosman DO, Rizzoli R, Pichard C, et al. Longitudinal measurement of regional and whole body bone mass in young healthy adults. Osteoporos Int 1994;4:18590.

28. Burger H, Van Daele, Algra D,et al. The association between age and bone mineral density in men and women aged 55 years and over: the Rotterdam Study. Bone Miner 1994;25:1-13.

29. Hannan MT, Felson DT, Anderson JJ. Bone mineral density in elderly men and women: results from the Framingham osteoporosis study. J Bone Miner Res 1992; 7:547-53.

30. Pouilles JM, Tremollieres F, Ribot C. Spine and femur densitometry at the menopause: are both sites necessary in the assessment of the risk of osteporosis? Calcif Tissue Int 1993;52:344-7.

31. Lai K, Rencken M, Drinkwater BL, Chesnut CH III. Site of bone density measurement may affect therapy decision. Calcif Tissue Int 1993;53:225-8.

32. Davis JW, Ross PD, Wasnich RD. Evidence for both generalized and regional low bone mass among elderly women. J Bone Miner Res 1994; 9:305-9.

33. Bonnick SL, Nichols DL, Sanborn CF, et al. Dissimilar spine and femoral Z-Scores in premenopausal women. Calcif Tissue Int 1997;61:263-5.

34. Molyvda-Athanasopoulou E, Sioundas A, Hathiioannou K. Dual energy X-ray absorptiometry reference data for Greek population. The impact on diagnosis of using various normal ranges for comparison. Eur J Radiol 2000;36:36-40.

35. Rubin CT, Lanyon LE. Regulation of bone mass by mechanical strain magnitude. Calcif Tissue Int 1985;37:56-61.

36. Suominen H. Bone mineral density and long term exercise: An overview of crosssectional athlete studies. Sports Med 1993;16:316-30.

37. Taaffe DR, Robinson TL, Snow CM, Marcus R. High-impact exercise promotes bone gain in well-trained female athletes. J Bone Miner Res 1997;12:255-60.

38. Krølner B, Toft B. Vertebral bone loss: an unheeded side effect of therapeutic bed rest. Clin Sci 1983;64:537-40.

39. Vogel J, Whittle M. Bone mineral changes: the second manned skylab mission. Aviat
Space Environ Med 1976;47:396-400.

40. Slemenda CW. Body composition and skeletal density mechanical loading or something more? J Clin Endocrinol Metab 1995;80:1761-3.

41. Schiessl H, Frost HM, Jee WSS. Estrogen and bone-muscle strength and mass relationships. Bone 1998;22:1-6.

42. Masud T, Langley S, Wiltshire $\mathrm{P}$, et al. Effect of spinal osteophytosis on bone mineral density measurements in vertebral osteoporosis. BMJ 1993;307:172-4.

43. Peel NFA, Barrington NA, Blumsohn A, et al. Bone mineral density and bone turnover in spinal osteoarthritis. Ann Rheum Dis 1995;54:867-71.

44. Cummings SR, Black DM, Nevitt MC, et al. Bone density of various sites for prediction of hip fractures. Lancet 1993;341:72-5.

45. Hannan MT, Felson DT, Anderson JJ. Bone mineraldensity in elderly men and women: Results from the Framingham osteoporosis study. J Bone Miner Res 1992;7:547-53.

46. Ensrud KE, Palermo L, Black DM, et al. Hip and calcaneal bone loss increases with advancing age. Longitudinal results from the study of osteoporotic fractures. J Bone Miner Res 1995;10:1778-87.

47. Jonell 0, Kannis AJ. An estimate of the worldwide prevalence and disability associated with osteoporotic fractures. Osteoporos Int 2006;17:1726-33.

48. Marquez AM, Melton LJ III, Muhs JM, et al. Bone density in an immigrant population from southeast asia. Osteoporos Int 2001; 12:595-604.

49. Jacobsen SJ, Sargent DJ, Atkinson EJ, et al. Contribution of weather to the seasonality of distal forearm fractures: a population-based study in Rochester, Minnesota. Osteoporos Int 1999;9:254-9. 